\title{
Peran Capacity Building terhadap Peningkatan Intellectual Capital Auditor Internal PTKIN di Indonesia dengan Audit Quality sebagai Variabel Intervening
}

\author{
Setyo Budi Hartono \\ Universitas Islam Negeri Walisongo Semarang \\ email: setyo_budi_hartono@walisongo.ac.id
}

\begin{abstract}
The objective of this study is to measure the capacity development of PTKIN auditors in Indonesia towards Intellectual Capital by using Audit Quality as a intervening variable. Resource-based theory as the basis for IC development that affects the accountability of PTKIN. Stakeholder theory is used as the basis of PTKIN in managing Budget Implementation. The methodology uses testing on 28 PTKIN auditors with questioner and WarpPLS 5.0 as a measuring tool. From the sample test it is known that the correlation between capacity building (CB) Audit Quality (AQ) has 53\% coefficient, capacity building (CB) to Intellectual Capital (IC) has 93\% coefficient, Audit Quality (AQ) significant to Intellectual Capital with coefficient - $16 \%$ And not significant, and the capacity building (CB) of Intellectual Capital (IC) with Audit Quality (AQ) as the mediation variable has coefficient - 80\% and has no effect on VAF $10 \%$. There is no factor influencing Intellectual Capital with Audit Quality as mediation variable to capacity building (CB). Intellectual Capital (IC) is strongly influenced by Audit Qualitys with appropriate educational backgrounds.
\end{abstract}

Keywords: capacity building; intellectual capital; audit quality

\begin{abstract}
Abstraks: Penelitian ini bertujuan untuk mengukur pengembangan kapasitas auditor PTKIN di Indonesia terhadap Intellectual Capital (IC) dengan menggunakan Audit Quality (AQ) sebagai variabel intervening. Resource Based Theory (RBT) digunakan sebagai dasar pengembangan IC yang akan memengaruhi akuntabilitas PTKIN. Teori stakeholder digunakan sebagai dasar PTKIN dalam mengelola implementasi Anggaran. Metodologi penelitian ini menggunakan pengujian pada 28 auditor PTKIN dengan kuesioner dan WarpPLS 5.0 sebagai alat ukur. Dari pengujian sampel diketahui hubungan antara Capacity Building (CB) Audit Quality (AQ) memiliki koefisien 53\%, Capacity Building (CB) terhadap Intellectual Capital (IC) memiliki koefisien 93\%, Audit Quality (AQ) signifikan terhadap Intellectual Capital (IC) dengan koefisien $-16 \%$ dan tidak signifikan, dan Capacity Building (CB) terhadap Intellectual Capital (IC) dengan Audit Quality (AQ) sebagai variabel intervening memiliki koefisien - 80\% dan tidak berpengaruh pada VAF $10 \%$. Tidak ada faktor yang berpengaruh terhadap Intellectual Capital (IC) dengan Audit Quality (AQ) sebagai variabel intervening terhadap Capacity Building (CB). Intellectual Capital (IC) sangat dipengaruhi oleh Audit Quality (AQ) dengan latar belakang pendidikan yang sesuai.
\end{abstract}

Kata Kunci: capacity building; intellectual capital; audit quality

Economica: Jurnal Ekonomi Islam - Volume 8, Nomor 2 (2017) 


\section{Pendahuluan}

Peran penting audit internal bagi Perguruan Tinggi yang berada di lingkungan Kementerian Agama adalah untuk memberikan keyakinan terhadap akuntabilitas penyelenggaraan negara (Siregar et al. 2011). Kualitas seorang audit dalam mengawal setiap kegiatan diperlukan untuk mengkonfigurasi bentuk tanggung jawab dan transparansi kepada publik, pencapaian tujuan yang efektif, efisien, ekonomis, dan etis (A.L. Watkins 2005). Perbaikan keseluruhan dalam Good University Governance (GUG) meliputi pelaksanaan reorganisasi utama, memperkuat manajemen pengeluaran publik melalui penyederhanaan dan penguatan treasury system dan proses, dan meningkatkan pendelegasian wewenang kepada departemen (Siregar et al. 2011). Dokumentasi dan manajemen keuangan sesuai dengan undangundang; perbaikan manajemen pendapatan, termasuk peningkatan transparansi dalam administrasi pajak; dan perbaikan secara bertahap dalam perencanaan ekonomi makro. Untuk mewujudkan semua tujuan tersebut diperlukan sebuah kualitas auditor yang bisa dicapai dengan meningkatkan kemampuan melalui capacity building secara berkelanjutan dalam menunjang Intellectual Capital bagi Perguruan Tinggi di lingkungan Kementerian Agama.

Kualitas audit (audit quality) didefinisikan sebagai probabilitas gabungan dari kemampuan seorang auditor untuk menemukan suatu pelanggaran dalam pelaporan keuangan klien, dan melaporkan pelanggaran tersebut (DeAngelo 1981). Para peneliti menyatakan bahwa tidak ada satu ukuran karakteristik tertentu yang dapat mewakili kualitas audit secara utuh karena kualitas audit memiliki sifat multidimensi (Bamber and Bamber 2009); (Francis 2004). Studi sebelumnya mengkritik penggunaan pengukuran kualitas audit yang konvensional (Bamber and Bamber 2009). Pengukuran kualitas audit sejauh ini lebih banyak menggunakan pengukuran tunggal, atau pengujian bersama dari beberapa pengukuran yang hanya mewakili salah satu dimensi kualitas audit, misalnya ukuran KAP (Big 5/6) (Becker et al. 1998) (J. K. Francis 2000); spesialisasi industri (Balsam, Krishnan, and Yang 
2003); lamanya masa penugasan audit/ pengalaman KAP (audit tenure) (Ghosh and Moon 2005). Berbeda dengan studi-studi sebelumnya, studi ini menguji hubungan intellectual capital pada Perguruan Tinggi di Kementerian Agama dengan pendekatan yang lebih komprehensif menggunakan pendekatan multidimensi terhadap peningkatan kualitas audit dengan treatment capacity building sebagai sarana pengembangannya.

Internal auditor pada Perguruan Tinggi di Lingkungan Kementerian Agama jumlahnya sangat terbatas dan kebanyakan bukan berasal dari latar belakang yang sesuai. Untuk menciptakan intellectual capital auditor internal bagi Perguruan Tinggi di lingkungan Kementerian Agama maka diperlukan alokasi investasi dalam bentuk capacity building guna meningkatkan kualitas audit. Capacity building merupakan kegiatan dalam pembentukan kulitas audit guna menciptakan intellectual capital (human capital, structural capital, and relationship capital).

Hiroyuki Itami dan Thomas W. Roehl (Hiroyuki Itami Roehl and Thomas W 1991) menyatakan bahwa sumber daya terdiri dari sumber daya fisik, manusia dan moneter yang diperlukan untuk kelangsungan operasi bisnis dan sumber daya berbasis informasi, seperti keterampilan manajemen, teknologi, informasi konsumen, nama merek, reputasi dan budaya perusahaan. Kunci bagi penciptaan intellectual capital adalah pengetahuan yang dimiliki oleh sebuah organisasi yang berasal dari pengetahuan pribadi yang dimiliki oleh seseorang dan pengetahuan eksplisit, dikodifikasikan dan disimpan oleh organisasi dan tersedia bagi individu di seluruh struktur (Ikujiro Nonaka Takeuchi and Hirotaka 1995). Aktiva tidak berwujud terbesar dalam setiap organisasi adalah orang-orang dan kecerdasan kolektif mereka. Ini berarti Intellectual Capital sebagian besar didorong oleh dan berasal dari sisi manusia dari perusahaan (Martin L.W. Hall 1998). Human capital berasal dari pengetahuan, keterampilan dan kecerdasan individu, proses berpikir dan tindakan yang diambil oleh individu yang mengakibatkan pembentukan structural capital dan relationship capital dari organisasi. 
Setyo Budi Hartono

Structural capital dan relationship capital internal auditor diklaim sebagai penerjemah bahasa akuntansi kepada para stakeholder dalam mengakuisisi kepentingan organisasi (Weil., et al., 2005). Fairchild (Fairchild 2007); Coate, et al., (Coates, Florence, and Kral 2002) menambahkan kredibilitas informasi keuangan dengan menyediakan verifikasi independen dari laporan keuangan yang disediakan manajemen akan mengurangi risiko informasi stakeholder. Kredibilitas pelaporan keuangan tercermin pada kepercayaan pengguna dalam laporan keuangan yang telah diaudit (A.L. Watkins 2005). Arthur Levitt (Levitt 2000) mempersepsikan kualitas audit memainkan peran penting dalam menjaga kepercayaan sistematis dalam integritas pelaporan keuangan bagi stakeholder.

Ketersediaan audit internal bagi Perguruan Tinggi di lingkungan Kementerian Agama jumlah dan latar belakangnya belum cukup memadai. Oleh karena itu capacity building diperlukan untuk meningkatkan kualitas di dalam meyakini proses audit yang diperlukan bagi akuntabilitas penyelenggaraan negara. Adapun perumusan masalah pada penelitian ini adalah: (1) Bagaimanakah pengaruh Capacity Building terhadap Intellectual Capital PTKIN?, (2) Bagaimanakah Audit Quality berpengaruh terhadap Intellectual Capital?, (3) Bagaimanakah pengaruh Capacity Building terhadap peningkatan Audit Quality?, dan (4) Bagaimakah pengaruh Capacity Building terhadap Intellectual Capital dengan Audit Quality sebagai variabel intervening?

Menganalisis pengaruh Capasity Building terhadap Intellectual Capital, pengaruh Capasity Bulding terhadap Audit Quality, pengaruh Audit Quality terhadap Intellectual Capital, dan pengaruh Capasity Building terhadap peningkatan Audit Quality yang akan dijadikan sebagai Intellectual Capital bagi Perguruan Tinggi di lingkungan Kementerian Agama dalam meyakini akuntabilitas penyelenggaraan negara. 
Peran Capacity Building terhadap Peningkatan Intellectual Capital...

\section{Landasan Teori}

\section{Resource Based Theory}

Capacity building adalah bentuk pengembangan intellectual capital (human capital) yang dihubungkan pada resource based theory. Perusahaan memiliki sumber daya yang dapat dijadikan sebagai keunggulan bersaing dan mengarahkan perusahaan untuk memiliki kinerja jangka panjang yang baik. Resources yang berharga dan langka dapat diarahkan untuk menciptakan keuanggulan bersaing, sehingga resources yang dimiliki mampu bertahan lama dan tidak mudah ditiru, ditransfer atau digantikan.

Barney dan Arikan (Jay B. Barney Arikan and Asli M 2001) menyatakan bahwa, "sumber daya adalah aset yang berwujud dan tidak berwujud yang digunakan untuk mengimplementasikan strategi". Menurut Pulic dan Kolakovic (Pulic and Kolakovic 2003), setiap perusahaan memiliki knowledge yang unik, ketrampilan, nilai dan solusi -intangible resource- yang dapat ditransformasikan menjadi 'nilai' di pasar. Pengelolaan sumber daya intangible dapat membantu perusahaan untuk mencapai keunggulan bersaing, meningkatkan produktivitas, dan nilai pasar.

Paparan Pulic dan Kolakovic (Pulic and Kolakovic 2003) ini sejalan dengan logika Barney (Barney 1991) ketika menjelaskan hubungan antara dua asumsi sumber daya dalam RBT dengan empat atribut sumber daya potensial untuk keunggulan bersaing berkelanjutan (sustained competitive advantages), perlu dibangun suatu model teoritis yang bermula dari sebuah asumsi bahwa sumber daya perusahaan adalah heterogen dan immobile. Agar menjadi sumber daya potensial dalam sustained competitive advantage, maka sumber daya perusahaan harus memiliki empat atribut, yaitu: (a) bernilai (valuable resources), (b) langka (rare resources), (c) tidak dapat ditiru (imperfecly imitable resource), (d) tidak ada sumber daya pengganti (nonsubtitutability resource). 
Setyo Budi Hartono

\section{Stakeholder Theory}

Laporan keuangan yang dihasilkan audit internal pada Perguruan Tinggi yang berada di lingkungan Kementerian Agama di Indonesia akan dipertanggungjawabkan kepada para stakeholder. Pimpinan PTKIN diharapkan untuk melakukan aktivitas yang dianggap penting oleh stakeholder mereka dan melaporkan kembali aktivitas-aktivitas tersebut pada stakeholder. Teori ini menyatakan bahwa seluruh stakeholder memiliki hak untuk disediakan informasi tentang bagaimana aktivitas organisasi memengaruhi mereka, bahkan ketika mereka memilih untuk tidak menggunakan informasi tersebut dan bahkan ketika mereka tidak dapat secara langsung memainkan peran yang konstruktif dalam kelangsungan hidup organisasi (Deegan 2004).

Lebih lanjut Deegan (Deegan 2004) menyatakan bahwa teori stakeholder menekankan akuntabilitas organisasi jauh melebihi kinerja keuangan atau ekonomi sederhana. Teori ini menyatakan bahwa organisasi akan memilih secara sukarela mengungkapkan informasi tentang kinerja lingkungan, sosial, dan intelektual mereka, melebihi dan di atas permintaan wajibnya, untuk memenuhi ekspektasi sesungguhnya atau yang diakui oleh stakeholder.

Capacity building yang diperuntukkan kepada audit internal difungsikan sebagai peningkatan kualitas audit dalam rangka menciptakan intellectual capital bagi masing-masing PTKIN dalam rangka menyesuaikan kepentingan stakeholder sebagai akuntabilitas semua kegiatan.

\section{Audit Quality}

Pengaruh kualitas audit yang tinggi diukur dengan suatu proksi tertentu (misalnya, Big 4, spesialisasi industri, audit tenure, client importance, audit opinion going cocern) Becker, et al. (Becker et al. 1998), Balsam, et al (Balsam, Krishnan, and Yang 2003); Gul, et al., (Gul, Fung, and Jaggi 2009); Geiger dan Rama (Geiger and Rama 2006). Ukuran KAP, misalnya Big 6/5/4 memiliki kualitas audit yang lebih tinggi dibandingkan dengan non Big 6/5/4 dengan 
argumentasi bahwa KAP besar memiliki pengetahuan, pengalaman tehnis, kapasitas, dan reputasi yang lebih superior dibandingkan KAP yang lebih kecil.

Becker, et al (Becker et al. 1998) serta Reynolds dan Francis (Reynolds and Francis 2000) menemukan bahwa klien Big 6 memiliki akrual diskresioner absolut yang lebih rendah dibandingkan dengan klien non Big 6 . KAP yang melakukan konsentrasi pada industri dan prosedur audit tertentu memungkinkan untuk memperoleh pengetahuan tentang bisnis dan industri klien dengan lebih banyak, sehingga KAP denhgan spesialisasi industri dapat bekerja lebih efektif (Watts and Zimmerman 1990).

\section{Pengembangan Teori Dasar}

\section{Hubungan Capacity Building dengan Audit Quality}

Menurut Shadreck dan Hebert (Shadreck 2013) pengaruh pelatihan terhadap kualitas para audit internal akan terlihat dari cara pemeriksaan dan hasil audit. Pengaruh positif terlihat ketika para audit internal diberikan pelatihan daripada sebelumnya.

H1: terdapat pengaruh positif antara capacity building dengan kualitas audit

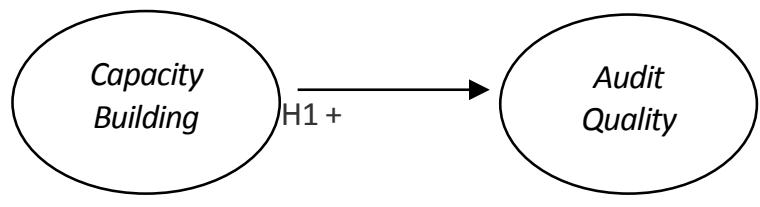

Hubungan Audit Quality dengan Intellectual Capital

Muhammad Dahlan (Dahlan 2009) dalam penelitiannya menemukan ada hubungan yang kuat antara kualitas audit dengan Intellectual Capital (human capital) pada BPK dan BPKP. Secara simultan tingkat pendidikan, pengalaman, tingkat kualifikasi profesi dan CPD memengaruhi kualitas 
auditor secara signifikan pada BPK dan BPKP. Secara parsial, pengalaman dan CPD mempengaruhi kualitas auditor secara signifikan.

H2: terdapat pengaruh positif antara kualitas audit dengan Intellectual Capital

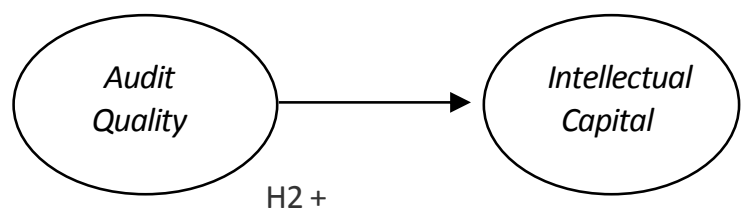

\section{Hubungan Capacity Building dengan Intellectual Capital}

T. Keban Yeremias (Yeremias 2004) mengungkapkan bahwa peningkatan kemampuan terhadap individu akan berpengaruh positif terhadap organisasi (structural capital) dan network (relationship capital). Pengembangan dimensi individu merupakan kunci utama atau titik strategis bagi perbaikan kinerja (Mentz 1997).

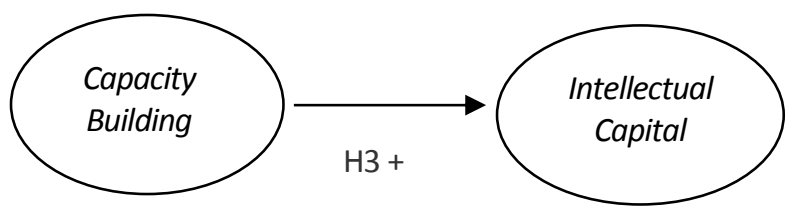

\section{Model Penelitian Empiris}

Penelitian ini dikembangkan untuk mengetahui pengaruh langsung (direct) capacity building terhadap Intellectual Capital, capacity building terhadap kualitas audi, serta pengaruh tidak langsung (indirect) capacity building terhadap Intellectual Capital dengan kualitas audit sebagai variabel intervening. 


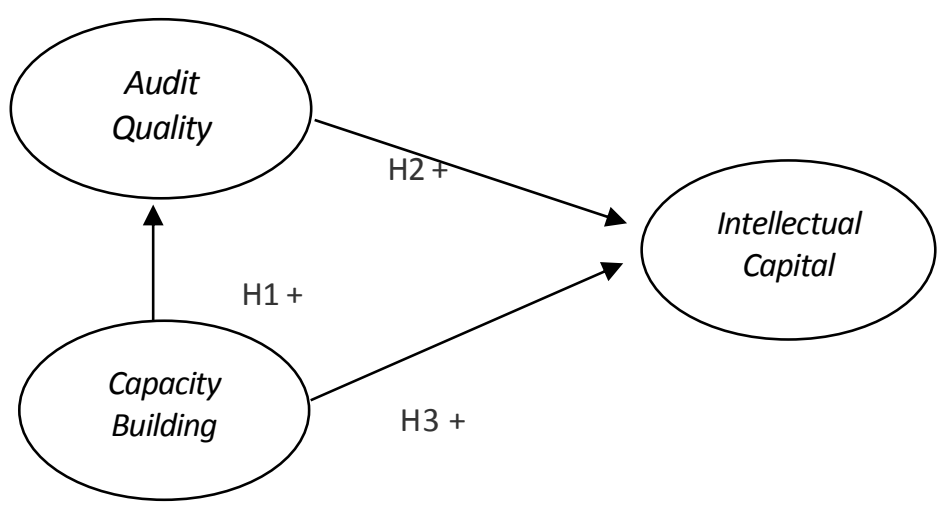

\section{Metode Penelitian}

\section{Sumber Data}

Sumber data pada penelitian ini adalah data sekunder yang diperoleh dari pembagian kuesioner kepada para audit internal Satuan Pengawas Internal (SPI) Perguruan Tinggi di lingkungan Kementerian Agama. Kuesioner tersebut berisikan pertanyaan-pertanyaan reflektif capacity building, kualitas audit, dan Intellectual Capital.

\section{Populasi dan Sampel}

Populasi penelitian ini adalah audit internal pada Satuan Pengawas Internal (SPI) pada Perguruan Tinggi di lingkungan Kementerian Agama yang berjumlah 45 orang. Penelitian ini menggunakan teknik sampling nonprobability dengan pertimbangan yang terkait dengan penghematan biaya, waktu dan tenaga serta keterandalan subjektifitas peneliti. Metode judgment sampling dipilih dengan menggunakan pertimbangan, kriteria, dan batasan tertentu sehingga sampel yang dipilih adalah yang paling relevan dengan tujuan penelitian (Sekaran 2003).

\section{Variabel Penelitian dan Pengukuran Variabel}

Definisi dan pengukuran variabel yang digunakan dalam penelitian ini dapat disajikan pada tabel di bawah ini: 
Setyo Budi Hartono

Tabel 1. Variabel, Definisi Konseptual, dan Definisi Operasional

\begin{tabular}{|c|c|c|}
\hline Variabel & Definisi Konseptual & Definisi Operasional \\
\hline $\begin{array}{l}\text { Eksogen } \\
\text { Capacity Building }\end{array}$ & $\begin{array}{l}\text { Pendekatan konseptual } \\
\text { untuk pembangunan sosial } \\
\text { atau pribadi yang berfokus } \\
\text { pada pemahaman kendala } \\
\text { yang menghambat orang, } \\
\text { pemerintah, organisasi } \\
\text { internasional dan organisasi } \\
\text { non-pemerintah dari tujuan } \\
\text { pembangunan mereka } \\
\text { sekaligus meningkatkan } \\
\text { kemampuan yang akan } \\
\text { memungkinkan mereka } \\
\text { untuk mencapai hasil yang } \\
\text { terukur dan berkelanjutan. }\end{array}$ & $\begin{array}{l}\text { 1. Pengembangan } \\
\text { Pengetahuan } \\
\text { - Standar Audit } \\
\text { - Pengetahuan Audit } \\
\text { - Pengalaman Audit } \\
\text { - Pelatihan Audit } \\
\text { 2. Spesifikasi } \\
\text { - Keahlian teknis Audit } \\
\text { - Mental Audit } \\
\text { - Independensi Audit } \\
\text { - Keahlian Bidang Audit } \\
\text { 3. Level } \\
\text { - Job description } \\
\text { - Job qualifications }\end{array}$ \\
\hline $\begin{array}{l}\text { Endogen } \\
\text { Intellectual Capital }\end{array}$ & $\begin{array}{l}\text { Materi intelektual yang telah } \\
\text { diformalisasi, ditangkap, dan } \\
\text { dimaanfaatkan untuk } \\
\text { memproduksi asset yang } \\
\text { nilainya lebih tinggi. Setiap } \\
\text { organisasi menempatkan } \\
\text { materi intelektual dalam } \\
\text { bentuk asset dan sumber } \\
\text { daya, perspektif dan } \\
\text { kemampuan eksplisit dan } \\
\text { tersembunyi, ,data, } \\
\text { informasi, pengetahuan, dan } \\
\text { mungkin kebijakan }\end{array}$ & $\begin{array}{l}\text { Pulic (1998; 1999; 2000) } \\
\text { menggunakan perhitungan } \\
\text { dalam: } \\
\text { 1) Intellectual Capital } \\
\text { - } \quad \text { Output (OUT) -APBN } \\
\text { dan pendapatan lain. } \\
\text { - } \quad \text { Input (IN) - Beban dan } \\
\text { biaya-biaya (selain } \\
\text { beban karyawan). } \\
\text { - Value Added (VA) - } \\
\text { Selisih antara Output } \\
\text { dan Input. } \\
\text { - Human Capital (HC) - } \\
\text { Beban karyawan. } \\
\text { - Capital Employed (CE) - } \\
\quad \text { Dana yang tersedia } \\
\text { (ekuitas, laba bersih) } \\
\text { - Structural Capital (SC) - } \\
\text { VA-HC } \\
\text { 1. Physical Capital (VACA) } \\
\text { - VACA = VA/CE }\end{array}$ \\
\hline
\end{tabular}


Peran Capacity Building terhadap Peningkatan Intellectual Capital...

\begin{tabular}{|c|c|c|}
\hline Variabel & Definisi Konseptual & Definisi Operasional \\
\hline & & $\begin{array}{l}\text { 2. Human Capital (VAHU) } \\
\text { - VAHU = VA/HC } \\
\text { 3. Structural Capital (STVA) } \\
\text { - STVA = SC/VA } \\
\left.\text { 4. Value Added (VAIC }{ }^{\mathrm{TM}}\right) \\
\text { - VAIC }{ }^{\mathrm{TM}}=\mathrm{VACA}+\mathrm{VAHU} \\
\text { +STVA }\end{array}$ \\
\hline $\begin{array}{l}\text { Intervening } \\
\text { Kualitas Audit }\end{array}$ & $\begin{array}{l}\text { Penilaian oleh pasar dimana } \\
\text { terdapat kemungkinan } \\
\text { auditor akan memberikan a) } \\
\text { penemuan mengenai suatu } \\
\text { pelanggaran dalam sistem } \\
\text { akuntansi klien; dan b) } \\
\text { adanya pelanggaran dalam } \\
\text { pencatatannya. } \\
\text { Kemungkinan bahwa } \\
\text { auditor akan melaporkan } \\
\text { adanya laporan yang salah } \\
\text { saji telah dideteksi dan } \\
\text { didefinisikan sebagai } \\
\text { independensi auditor. }\end{array}$ & $\begin{array}{l}\text { Reynolds dan Francis (2001) } \\
\text { Frankel et al., (2002) ukuran } \\
\text { kualitas audit: } \\
\text { 1. Afiliasi KAP (Big Four) } \\
\text { 2. Spesialisasi } \\
\text { - Keahlian } \\
\text { - Kesesuaian } \\
\text { - Jumlah auditor } \\
\text { - Lama bekerja } \\
\text { - Jumlah APBN } \\
\text { 3. Tenor masa kerja Auditor } \\
\text { Internal SPI } \\
\text { - Lama bekerja } \\
\text { - Mobilisasi } \\
\text { 4. Client Importance } \\
\text { - Pengaruh lingkungan } \\
\text { - Kematangan emosional }\end{array}$ \\
\hline
\end{tabular}

\section{Metode Analisis}

Metode analisis yang digunakan untuk menguji hipotesis adalah path analysis atau analisis jalur. Analisis jalur merupakan regresi simultan dengan variabel observed atau terukur secara langsung (Latan 2014). Analisis jalur menganalisis hubungan yang terjadi karena pengaruh langsung dan tidak langsung dari variabel independen terhadap variabel dependen, menganalisis ketergantungan sejumlah variabel dalam suatu model kausal yang telah

Economica: Jurnal Ekonomi Islam - Volume 8, Nomor 2 (2017) 
dirumuskan oleh peneliti atas dasar hipotesis kausal dan menginterpretasi hubungan.

Penelitian ini menggunakan alat analisis Partial Least Square (PLS) dengan software warpPLS versi 4.0 untuk menguji hipotesis. PLS dipilih karena dapat mengatasi masalah data yang timbul dalam ordinary least square yang digunakan dalam analisis regresi data panel. Bila data yang dimiliki jumlah observasinya kecil, banyak missing value dan terdapat multikolinearitas antar variabel independen, maka hasil regresi OLS akan tidak stabil dan adanya multikol antar variabel independen akan mengakibatkan standar error dari koefisien yang diestimasi (Latan 2014).

\section{Data dan Sampel}

Metode pengambilan sampel dalam penelitian ini menggunakan metode purposive sampling yaitu dengan menggunakan pertimbangan dan batasan tertentu sehingga sampel yang dipilih relevan dengan tujuan penelitian. Sampel pada penelitian ini adalah auditor yang mengembalikan kuesioner sebanyak 28 orang dari jumlah populasi sebanyak 45 auditor di SPI PTKIN seluruh Indonesia. Pemilihan sampel untuk melihat terpenuhinya asumsiasumsi dalam teori dan tujuan dari penelitian.

\section{Hasil dan Pembahasan}

Penelitian ini menggunakan data sekunder, dimana variabel yang digunakan merupakan variabel yang memiliki satu kontruk formatif. Tujuan penelitian ini adalah untuk menguji efek mediasi kualitas audit dalam hubungan antara pembangunan Capacity Building audit internal dengan Intellectual Capital yang akan didapat PTKIN dari pembangunan.

Hasil pengujian full model penelitian dengan WarpPLS 5.0 disajikan pada gambar dan tabel di bawah ini. Berdasarkan output model fit and quality indices model mempunyai nilai Average Path Coefficient (APC) $=0.541$, $\mathrm{P}<0.001$, Average R-squared (ARS) $=0.469, \mathrm{P}<0.001$, Average Adjusted $R$ - 
squared $(\mathrm{AARS})=0.442, \mathrm{P}<0.001$, Average Block VIF $(\mathrm{AVIF})=2.337$, acceptable if $<=5$, ideally $<=3.3$, Average Full collinearity $\operatorname{VIF}(\mathrm{AFVIF})=2.187$, acceptable if $<=5$, ideally $<=3.3$, Tenenhaus GoF $(\mathrm{GoF})=0.403$, small $>=0.1$, medium $>=0.25$, large $>=0.36$. Nilai P untuk APC dan ARS harus lebih kecil dari 0,05 taua berarti signifikan. Dari hasil tersebut dapat dilihat bahwa nilai $\rho$ untuk APC dan ARS lebih kecil dari 0,05. Nilai AVIF sebagai indikator multikolinearitas harus lebih kecil dari 5. Dari data tersebut didapat nilai 2,337 maka nilai AVIF memenuhi kriteria.

Tabel 2 . Model Fit and Quality Indices, Path Coefisiens, dan $\rho$-Value, Indirect Effect, Total Effect, Effect Size-Full Model

\begin{tabular}{|c|c|c|}
\hline \multicolumn{3}{|c|}{ Model Fit and Quality Indices } \\
\hline \multicolumn{3}{|c|}{$A P C=0.541, P<0.001$} \\
\hline \multicolumn{3}{|c|}{ ARS $=0.469, P<0.001$} \\
\hline \multicolumn{3}{|c|}{ AARS $=0.442, P<0.001$} \\
\hline \multicolumn{3}{|c|}{ AVIF $=2.337$, acceptable if $<=5$, ideally $<=3.3$} \\
\hline \multicolumn{3}{|c|}{ AFVIF $=2.187$, acceptable if $<=5$, ideally $<=3.3$} \\
\hline \multicolumn{3}{|c|}{ GoF $=0.403$, small $>=0.1$, medium $>=0.25$, large $>=0.36$} \\
\hline Jalur & Coefficients & $\rho$-value \\
\hline $\mathrm{CB} \rightarrow \mathrm{AQ}$ & 0.527 & $<.001$ \\
\hline $\mathrm{AQ} \rightarrow \mathrm{IC}$ & -0.165 & 0.176 \\
\hline $\mathrm{CB} \rightarrow \mathrm{IC}$ & 0.931 & $<.001$ \\
\hline Indirect Effect & Coefficients & $\rho$-value \\
\hline $\mathrm{CB} \rightarrow \mathrm{IC}$ & -0.087 & 0.252 \\
\hline Total Effect & Coefficients & $\rho$-value \\
\hline $\mathrm{CB} \rightarrow \mathrm{AQ}$ & 0.144 & $<.001$ \\
\hline $\mathrm{AQ} \rightarrow \mathrm{IC}$ & 0.174 & 0.176 \\
\hline $\mathrm{CB} \rightarrow \mathrm{IC}$ & 0.117 & $<.001$ \\
\hline Effect Size & Coef & \\
\hline $\mathrm{CB} \rightarrow \mathrm{IC}$ & & \\
\hline $\mathrm{CB} \rightarrow \mathrm{AQ}$ & & \\
\hline $\mathrm{AQ} \rightarrow \mathrm{IC}$ & & \\
\hline Indirect Effect & Coef & \\
\hline $\mathrm{CB} \rightarrow \mathrm{IC}$ & & \\
\hline
\end{tabular}

Sumber: Data olahan digunakan dalam penelitian ini

Economica: Jurnal Ekonomi Islam - Volume 8, Nomor 2 (2017) http://journal.walisongo.ac.id/index.php/economica 
Setyo Budi Hartono

$\begin{array}{llll}\text { APC } & \text { : Average Path Coefficient } & \text { ARS } & \text { Average R-Squared } \\ \text { AARS } & : \text { Average Adjusted R-Squared } & \text { AVIF : Average block VIF } \\ \text { AFVIF } & : \text { Average Full Collinearity } & \text { GoF : Tenenhaus GoF } \\ \text { CB } & : \text { Capacity Building } & \text { AQ : Audit Quality } \\ \text { IC } & \text { : Intellectual Capital } & & \end{array}$

Tabel di bawah menyajikan R-Squared $\left(\mathrm{R}^{2}\right), Q$ Square $\left(\mathrm{Q}^{2}\right)$ dan full Collinearity VIF. $\mathrm{R}^{2}$ dapat digunakan untuk menjelaskan pengaruh variabel laten eksogen terhadap variabel laten endogen apakah mempunyai pengaruh yang substansif. $\mathrm{Q}^{2}$ digunakan untuk mengetahui apakah model mempunyai predictive relevance atau tidak. Nilai $Q^{2}>0$ menunjukkan model mempunyai predictive relevance sedangkan nilai $\mathrm{Q}^{2}<0$ menunjukkan model kurang memiliki predictive relevance. Sedangkan full collinearity VIF merupakan hasil pengujian kolinearitas penuh yang meliputi multikolinearitas vertikal dan lateral. Kriteria untuk full collinearity tes adalah nilainya harus lebih rendah 3.3 (Kock 2010).

Hasil pengujian menunjukkan nilai $\mathrm{R}^{2}$ masing-masing variabel endogen adalah 27,7\% (AQ), 66,1\% (IC). Model penelitian ini mempunyai predictive relevance karena mempunyai $\mathrm{Q}^{2}$ di atas 0 . Berdasarkan nilai full Collinearity VIF yang berada di bawah 3.3 menunjukkan di dalam model penelitian tidak terdapat multikolineritas.

Tabel 3. R-Square, Q-Square dan Full Collinearity VIF

\begin{tabular}{lll}
\hline \multicolumn{3}{c}{ R-Square } \\
\hline $\mathrm{AQ}$ & & 0.277 \\
$\mathrm{IC}$ & Q-Square & 0.661 \\
& & \\
$\mathrm{AQ}$ & & 0.279 \\
$\mathrm{IC}$ & 0.682 \\
& & \\
$\mathrm{CB}$ & Full Collinearity VIF & 2.692 \\
$\mathrm{AQ}$ & & 1.382 \\
$\mathrm{IC}$ & & 2.488 \\
\hline
\end{tabular}

Sumber: Data olahan digunakan dalam penelitian ini
CB : Capacity Building
IC : Intellectual Capital
$A Q$ : Audit Quality 


\section{Hasil Penelitian}

Gambar di bawah ini menunjukkan koefisien jalur dan nilai $\rho$ dari setiap hubungan langsung (direct effect), hubungan tidak langsung (indirect effect), total effect dan effect size dalam model penelitian. Jalur CB $\rightarrow$ IC menunjukkan nilai koefisien 0.931 dan sigmifikan dengan nilai $\rho<0.001$. Jalur $C B \rightarrow A Q$ menunjukkan nilai koefisien 0.527 dan sigmifikan dengan nilai $\rho<0.01$. Dan jalur AQ $\rightarrow$ IC menunjukkan nilai koefisien - 0.165 dan tidak signifikan. Jalur tidak langsung/indirect effect CB $\rightarrow$ IC menunjukkan nilai koefisien -0.087 dan tidak signifikan.

Gambar 1. Koefisien Jalur dan Nilai $\rho$ pada Setiap Hubungan

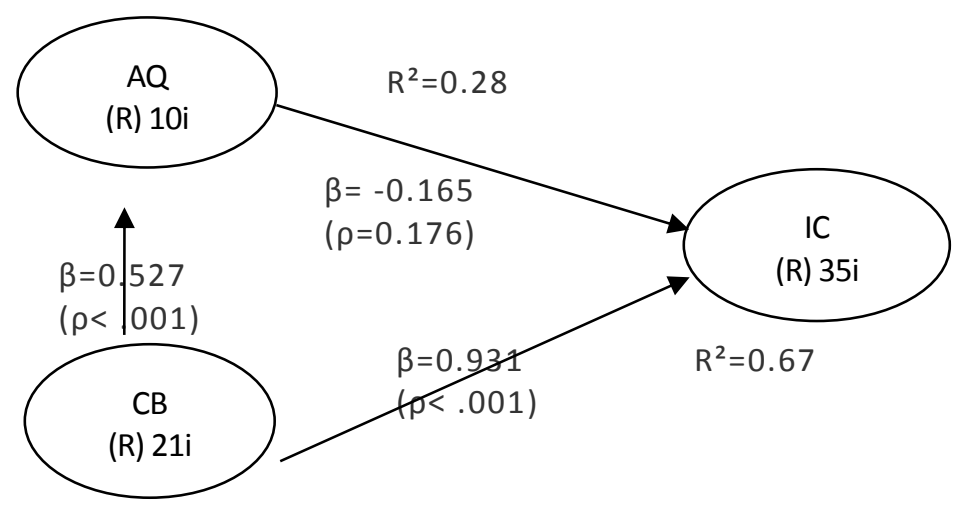

Sumber: Data olahan digunakan dalam penelitian ini

\section{Pengujian Hipotesis 1}

Hipotesis pertama menyatakan bahwa Capacity Building (CB) berpengaruh positif terhadap Audit Quality (AQ). Untuk membuktikan hipotesis ini dilakukan pengujian langsung (direct effect) dan hasilnya tersaji dalam gambar di bawah ini. 


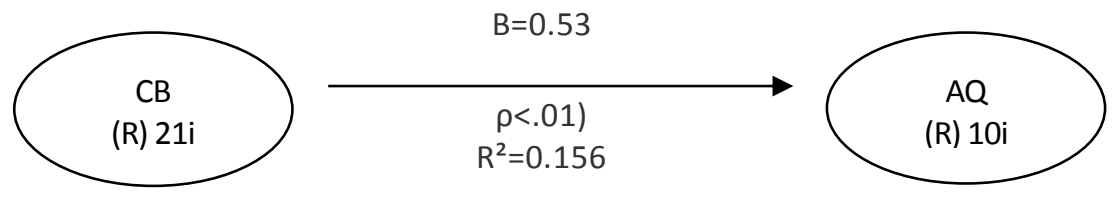

Tabel 4. Pengujian Hipotesis

\begin{tabular}{|c|c|}
\hline & $\mathrm{CB} \rightarrow \mathrm{AQ}$ \\
\hline \multicolumn{2}{|c|}{ Model Fit and Quality Indices } \\
\hline \multicolumn{2}{|c|}{$\mathrm{APC}=0.527, \mathrm{P}<0$} \\
\hline \multicolumn{2}{|c|}{ ARS $=0.277, P=0.026$} \\
\hline \multicolumn{2}{|c|}{ AARS $=0.250, P=0.036$} \\
\hline \multicolumn{2}{|c|}{ AFVIF $=1.367$, acceptable if $<=5$, ideally $<=3.3$} \\
\hline \multicolumn{2}{|c|}{ GoF $=0.301$, small $>=0.1$, medium $>=0.25$, large $>=0.36$} \\
\hline \multicolumn{2}{|c|}{ Path Coefisiens dan $\rho$-value } \\
\hline $\mathrm{CB} \rightarrow \mathrm{AQ}$ & $\rho<0.001$ \\
\hline \multicolumn{2}{|l|}{ R-Squareed } \\
\hline $\mathrm{CB} \rightarrow \mathrm{AQ}$ & 0.156 \\
\hline \multicolumn{2}{|l|}{ Effect size } \\
\hline $\mathrm{CB} \rightarrow \mathrm{AQ}$ & 0.156 \\
\hline
\end{tabular}

Sumber: Data olahan digunakan dalam penelitian ini

Berdasarkan tabel di atas diketahui bahwa kriteria model fit telah terpenuhi, dimana APC, ARS, AARS berada dibawah 0.05, nilai AFVIF $<5$ dan nilao GoF termasuk medium yaitu 0.301 . koefisien jalur yang dihasilkan 0.53 dan signifikan dengan nilai $\rho<0.001$. Dengan demikian dapat disimpulkan bahwa "hipotesis 1 diterima." Artinya Capacity Building (CB) berpengaruh positif signifikan terhadap Audit Quality (AQ) dengan nilai koefisien determinasi sebesar 0.156 .

\section{Pengujian Hipotesis 2}

Hipotesis kedua menyatakan bahwa Audit Quality (AQ) berpengaruh positif terhadap Intellectual Capital (IC). Berdasarkan output WarpPLS yang tersaji dalam tabel di atas diketahui nilai jalur koefisiennya adalah -0.165 dan 
tidak signifikan. Dengan demikian dapat disimpulkan bahwa "hipotesis 2 ditolak".

Hasil penelitian ini bertolak belakang dengan penelitian sebelumnya yang dilakukan oleh Faisal, dkk (Faisal 2012), dimana didapatkan hasil antara Audit Quality terhadap Intellectual Capital. Dengan kata lain semakin tinggi kualitas dari seorang auditor maka akan berpengaruh tinggi terhadap Intellectual Capital pada organisasi tersebut. Akan tetapi, Bamber, E.M \& Bamber, L.S. (Bamber and Bamber 2009) berpendapat, "kualitas auditor dapat dilihat dari kualitas Aparat Pengawas Internal Pemerintah melalui sikap profesionalisme dan independensinya". Manfaat dengan adanya profesionalisme dan independensi dapat meningkatkan hasil audit sehingga mampu memberikan kepercayaan kepada masyarakat. Namun sering kali seorang auditor internal pada entitas pemerintahan tidak sesuai dengan bidang akuntan dan seringkali berada dalam kondisi yang dilematis, merasa sulit untuk menjaga profesionalisme dengan satuan unit kerja yang diaudit sementara kode etik profesi menuntutnya untuk selalu profesionalisme dalam pekerjaannya. Jika tidak menjaga profesionalisme akan menyalahi kode etik profesi tersebut dan memperburuk kualitas hasil audit, dan konsistensi profesionalisme akan berakibat salah dalam menganalisi kasuskasus kecurangan yang bersifat material, yang dapat menyeret banyak pihak, dan justru dapat memperburuk citra institusi.

\section{Pengujian Hipotesis 3}

Hipotesis ketiga menyatakan bahwa Capacity Building (CB) berpengaruh positif terhadap Intellectual Capital (IC). Berdasarkan output WarpPLS yang tersaji dalam tabel di atas diketahui nilai jalur koefisiennya adalah 0.931 dan memiliki nilai $\rho<0.001$. Dengan demikian dapat disimpulkan bahwa "hipotesis 3 diterima' dengan nilai koefisien determinasi sebesar 0.67 . 
Setyo Budi Hartono

\section{Pengujian Hipotesis 4}

Hipotesis keempat digunakan dalam mengestimasi hubungan tidak langsung (indirect effect) antara Capacity Building (CB) dan Intellectual Capital (IC) dengan memasukkan Audit Quality (AQ) sebagai mediasi. Baron dan Kenny (Kenny 1986) mengungkapkan ada 4 prosedur yang harus dipenuhi dalam menguji pengaruh mediasi penelitian:

1. Pengaruh langsung variabel independen/variabel eksogen terhadap variabel mediasi harus signifikan.

2. Pengaruh langsung variabel independen/variabel eksogen terhadap variabel independen/endogen harus signifikan saat variabel pemediasi belum dimasukkan ke dalam model.

3. Menguji secara simultan pengaruh variabel eksogen dan variabel mediasi terhadap variabel independen/endogen. Setelah variabel pemediasi dimasukkan ke dalam model maka pengaruh tidak langsung harus signifikan.

4. Pengujian tambahan untuk melihat efek mediasi menurut Ghozali dan Latan (Latan 2014) dan Sholihin dan Ratmono (Mahfud Sholihin dan Dwi Ratmono 2014) adalah dengan menggunakan pendekatan Hair, et. al., (Joe F. Hair Jr 2014) yaitu menghitung VAF. Jika nilai VAF di atas $80 \%$, menunjukkan mediasi penuh (full mediation). Jika VAF bernilai $20-80 \%$, dapat dikategorikan sebagai pemediasi parsial (parcial mediation). Nilai VAF jika kurang dari 20\% dapat disimpulkan bahwa hampir tidak ada efek mediasi.

Dari hasil output WarpPLS dapat diketahui bahwa jalur $\mathrm{CB} \rightarrow \mathrm{AQ}$ signifikan, jalur $\mathrm{CB} \rightarrow$ IC signifikan, dan jalur $\mathrm{CB} \rightarrow$ IC dengan mediasi $\mathrm{AQ}$ signifikan dengan koefisien indirect effect -0.087 dengan $\rho=0.252$ tidak signifikan sehingga "hipotesis 4 ditolak". 
Menghitung nilai VAF dengan rumus:

VAF

$$
\begin{aligned}
& =\frac{\text { Pengaruh tidak langsung/indirect effect }}{\text { Pengaruh Total (pengaruh langsung }+ \text { pengaruh tidak langsung) }} \\
& \mathrm{VAF}=\frac{-0.087}{0.931+(-0.087)}
\end{aligned}
$$$$
\mathrm{VAF}=-0.103=-10 \% \text { nilai absolutnya adalah } 10 \%
$$

Nilai VAF sebesar 10\% menunjukkan bahwa Audit Quality tidak memiliki pengaruh mediasi Capacity Building terhadap Intellectual Capital.

\section{Kesimpulan Hasil Pengujian Hipotesis Penelitian}

Kesimpulan umum dalam pengujian hipotesis untuk menjawab pertanyaan penelitian dapat dilihat pada tabel di bawah ini:

\begin{tabular}{|c|c|c|}
\hline Hipotesis & Hasil Pengujian & Kesimpulan \\
\hline $\begin{array}{l}\text { Hipotesis 1: } \\
\text { Capacity Building (CB) berpengaruh } \\
\text { positif terhadap Audit Quality (AQ). }\end{array}$ & $\begin{array}{l}\text { Signifikan }(+) \\
\text { Koefisien } 0.53 \\
\text { Nilai } \rho<.001\end{array}$ & DITERIMA \\
\hline $\begin{array}{l}\text { Hipotesis 2: } \\
\text { Audit Quality (AQ) berpengaruh positif } \\
\text { terhadap Intellectual Capital (IC) }\end{array}$ & $\begin{array}{l}\text { Signifikan }(-) \\
\text { Koefisien }-0.163 \\
\text { Nilai } \rho=0.176\end{array}$ & DITOLAK \\
\hline $\begin{array}{l}\text { Hipotesis 3: } \\
\text { Capacity Building (CB) berpengaruh } \\
\text { positif terhadap Intellectual Capital (IC) }\end{array}$ & $\begin{array}{l}\text { Signifikan }(+) \\
\text { Koefisien } 0.931 \\
\text { Nilai } \rho<.001\end{array}$ & DITERIMA \\
\hline $\begin{array}{l}\text { Hipotesis 4: } \\
\text { Audit Quality (AQ) memediasi } \\
\text { hubungan antara Capacity Building (CB) } \\
\text { dan Intellectual Capital (IC) }\end{array}$ & $\begin{array}{l}\text { Signifikan (-) } \\
\text { VAF } 10 \%\end{array}$ & DITERIMA \\
\hline
\end{tabular}

Tabel 5. Pengujian Hipotesis

Economica: Jurnal Ekonomi Islam - Volume 8, Nomor 2 (2017) 
Setyo Budi Hartono

\section{Pembahasan}

\section{Pengaruh Capacity Building (CB) terhadap Audit Quality (AQ)}

Hipotesis 1 menyatakan bahwa Capacity Building (CB) berpengaruh positif terhadap Audit Quality (AQ). Berdasarkan output WarpPLS sebagaimana yang disajikan pada gambar dan tabel di atas dan kriteria model fit telah terpenuhi. Koefisian yang dihasilkan adalah 0.53 dengan nilai $\rho<0.01$ dengan nilai koefisien determinasi sebesar 0.156 dapat disimpulkan bahwa hipotesis 1 diterima. Capacity Building (CB) berpengaruh positif pada Audit Quality (AQ) atau Audit Quality (AQ) memiliki reaksi positif terhadap Capacity Building (CB) yang dilakukan oleh PTKIN.

Hasil penelitian ini dapat dikonfirmasi pada data penelitian Trisdiono (Trisdiono 2016) yang menunjukkan indikasi yang sama. Penelitian ini dilakukan untuk mengetahui keefektifan dan dampak (effect size) diklat capacity building audit mutu internal tingkat Provinsi D.I. Yogyakarta tahun 2015. Penelitian dilakukan dengan metode kuantitatif dan didukung analisis kualitatif. Subjek penelitian sebanyak 140 orang peserta diklat yang terbagi dalam tiga rombongan belajar. Subjek terdiri dari 74 orang audit junior dan 66 orang audit senior. Berdasarkan jenis kelamin subjek terdiri dari 50 orang Laki-laki dan 90 orang Perempuan. Data diperoleh dari hasil pre dan post test. Hasil analisis menunjukkan bahwa t-test sebesar 1,84E-15 yang berarti $\leq 0,05$, sehingga keefektifannya signifikan dalam tingkat kepercayaan 95\%. Diklat Capacity Building audit mutu internal tingkat Provinsi D.I. Yogyakarta tahun 2015 memiliki dampak yang besar terhadap kualitas audit yang ditunjukkan dari nilai effect size sebesar 0,80 .

Capacity Building merupakan suatu kegiatan yang dilakukan untuk meningkatkan kemampuan pada level pelaksana, kemampuan teknis terutama Pengendalian Mutu dan Teknis agar menciptakan kemampuan yang merata. Holbert (Holbert 2014) fokus Capacity Building adalah peningkatan 
kemampuan dalam bidang audit yang akan mempengaruhi kualitas hasil akhir pemeriksaan melalui kualitas Laporan Hasil Pemeriksaan Kinerja.

Berdasarkan teori stakeholder theory mengungkapkan bahwa keberlangsungan perusahaan mensyaratkan dukungan para stakeholder, kepentingan mereka harus diperhatikan dan aktivitas perusahaan seharusnya diarahkan untuk memenuhi ekspektasi mereka. Semakin berkuasa stakeholder, semakin banyak perusahaan harus beradaptasi (Gray, Kouhy, and Lavers 1995). Secara harfiah definisi stakeholder telah menuntut organisasi untuk mengembangkan semua sumber dayanya kepada pemenuhan kepentingan stakeholder.

\section{Pengaruh Audit Quality (AQ) terhadap Intellectual Capital (IC)}

Hipotesis 2 menyatakan bahwa Audit Quality (AQ) berpengaruh positif terhadap Intellectual Capital (IC). Berdasarkan output WarpPLS sebagaimana yang disajikan pada gambar dan tabel di atas dan diketahui kriteria model tidak terpenuhi. Koefisien yang dihasilkan adalah -0.165 dengan nilai $\rho=0.176$ dengan nilai koefisien determinasi sebesar 0.67 dapat disimpulkan bahwa hipotesis 2 ditolak. Audit Quality ((AQ) berpengaruh negatif pada Intellectual Capital atau kualitas auditor yang dimiliki oleh PTKIN di Indonesia adalah rendah.

Auditor yang dimiliki oleh PTKIN banyak yang berlatar belakang dari bidang yang tidak sesuai. Kemajemukan dari latar belakang auditor inilah yang menyebabkan kualitas audit yang rendah. Menurut Yulius Jogi Christiawan (Christiawan 2002), kualitas audit ditentukan oleh kompetensi dan independensi. Kompetensi berkaitan dengan pendidikan dan pengalaman memadai yang dimiliki akuntan publik dalam bidang auditing dan akuntansi. Sedangkan independensi merupakan salah satu komponen etika yang harus dijaga oleh akuntan publik. Kemampuan audit dipengaruhi oleh latar belakang akuntan dan akan berkembang ketika terjadi interaksi 
antara auditor dengan klien yang seharusnya mampu mengakomodasi kualitas audit secara optimal.

Masa perikatan yang terlalu singkat waktunya dapat menyebabkan pengetahuan spesifik tentang klien masih sedikit sehingga kualitas audit rendah. Jika terlampau panjang bisa menyebabkan turunnya independensi dan obyektivitas akibat keakraban berlebihan antara kedua pihak (Permana 2012). Mgbame, et al., (Mgbame et al. 2009) dalam penelitian yang dilakukan di Nigeria membuktikan secara empiris bahwa adanya hubungan negatif antara masa perikatan (audit tenure) dengan kualitas audit. Penelitian yang dilakukan oleh Giri (Giri 2010) membuktikan bahwa variabel audit tenure berpengaruh negatif dan signifikan terhadap variabel kualitas audit. Siregar, dkk (Siregar et al. 2011) menemukan bukti bahwa masa perikatan (audit tenure) memengaruhi rendahnya kualitas audit sebelum rotasi mandatory auditor diterapkan. Sebaliknya setelah rotasi mandatory auditor diterapkan masa perikatan (audit tenure) yang lama meningkatkan kualitas audit.

Dari hasil penelitian ini masa penugasan (audit tenure) diketahui memiliki rata-rata penugasan di PTKIN masih rendah dan masih di bawah 3 (tiga) tahun sehingga ini sangat berpengaruh terhadap kualitas audit. Pernyataan penelitian yang sama juga mendukung adanya pengaruh yang negatif dari masa penugassan yang masih singkat terhadap kualitas audit (Gómez-Aguilar 2008). Masa penugasan yang masih singkat ini menyebabkan rendahnya kualitas auditor karena bidang audit, afiliasi, spesialisasi, pengalaman, keahlian, unit yang diaudit, dan besaran anggaran yang diaudit masih belum dilakukan secara menyeluruh (Beasley 1996); (Chen and Jaggi 2000). Menurut Larcker, et al., (David F Larcker 2005) cara terbaik di dalam meningkatkan kualitas audit dengan masa penugasan yang masih rendah adalah dengan mengkombinasikannya dengan audit yang sudah memiliki pengalaman. 


\section{Pengaruh Capacity Building (CB) terhadap Intellectual Capital (IC)}

Hipotesis 3 menyatakan bahwa capacity building (CB) berpengaruh positif terhadap Intellectual Capital (IC). Berdasarkan output WarpPLS sebagaimana yang disajikan pada gambar dan tabel diatas dan diketahui kriteria model fit telah terpenuhi. Koefisian yang dihasilkan adalah 0.93 dengan nilai $\rho<0.01$ dengan nilai koefisien determinasi sebesar 0.156 dapat disimpulkan bahwa hipotesis 3 diterima. Capacity Building (CB) berpengaruh positif pada Audit Quality (AQ) atau Audit Quality (AQ) memiliki reaksi positif terhadap capacity building yang dilakukan oleh PTKIN.

Dalam penelitian Anzam et al., (2012) diungkapkan bahwa Capacity Building (CB) dapat meningkatkan kemampuan auditor baik individu, grup, organisasi, komunitas dan masyarakat dengan effect size 73\%. Youndt, et al., (Youndt, Subramaniam, and Snell 2004) menguraikan dua bentuk modal sosial konfigurasi peningkatan SDM - Intellectual Capital (IC). Yang pertama berkaitan dengan menghilangkan hambatan vertikal melalui praktik-praktik yang menghilangkan simbol status, mengurangi tingkat hirarki dan meminimalkan klasifikasi pekerjaan. Kedua berkaitan dengan menghilangkan hambatan horisontal dengan mendorong jaringan sosial dan kolaborasi melalui penggunaan praktik pengembangan tim dan insentif kelompok. Brown dan Duguid (Brown and Duguid 2001) berargumen bahwa pengetahuan organisasi diperoleh dari berbagi praktek-praktek sosial anggotanya, konfigurasi human resource yang meningkatkan modal sosial organisasi dalam memberikan kontribusi yang signifikan dari daya potensi dengan membangun intensitas kapasitas bagi human resource.

\section{Pengaruh Audit Quality (AQ) Memediasi Capacity Building (CB) terhadap Intellectual Capital (IC)}

Pada pengujian Capacity Building (CB) terhadap Intellectual Capital (IC) dengan menggunakan Audit Quality (AQ) sebagai variabel mediasi menunjukkan hasil output dengan WarpPLS sebagaimana yang disajikan pada gambar 
dan tabel di atas dapat diketahui kriteria model fit telah terpenuhi. Koefisien yang dihasilkan adalah -0.087 dengan nilai $\rho=0.252$ dapat disimpulkan bahwa pengaruh Capacity Building (CB) terhadap Intellectual Capital (IC) dengan menggunakan Audit Quality (AQ) sebagai variabel mediasi tidak memiliki pengaruh dengan nilai VAF $10 \%$.

Hasil penelitian ini sesuai dengan hipotesis 2 yang menyatakan koefisien yang dihasilkan dari pengaruh Audit Quality (AQ) terhadap Intellectual Capital (IC) adalah -0.165 dengan nilai $\rho=0.176$ dengan nilai koefisien determinasi sebesar 0.67 dan dapat disimpulkan bahwa Audit Quality (AQ) berpengaruh negatif terhadap Intellectual Capital (IC). Pengaruh mediasi tidak ada dikarenakan masa perikatan yang terlalu singkat waktunya dapat menyebabkan pengetahuan spesifik tentang klien masih sedikit sehingga kualitas audit rendah.

Herusetya (Herusetya 2012) menyatakan seluruh hasil statistik deskriptif variabel pengujian kualitas audit terhadap Intellectual Capital memiliki standar deviasi yang kecil, kecuali MTB dan SIZE menandakan tingkat variasi data rendah, dengan tingkat kemencengan yang rendah (skewness \pm 0 -2) (Acock 2008). Rata-rata sampel perusahaan yang diaudit oleh KAP Big 4 adalah 67,60\%, dengan 36,30\% KAP memiliki kapasitas sebagai spesialisasi industri (SPCL). Rata-rata perusahaan sampel yang diaudit dengan masa penugasan audit (tenure) berkisar $>3$ tahun dan $<9$ tahun adalah 27,10\%. Persentase KAP yang tidak memiliki ketergantungan ekonomi yang dapat mengancam independensi adalah 87,60\%, dengan tingkat kesediaan melaporkan dan memiliki kualitas pelaporan audit sebesar 45,70\%. Sedangkan rata-rata kriteria kualitas audit yang tinggi menggunakan pendekatan multidimensi (AQMS) adalah 52,80\%. Studi ini juga menemukan bahwa rata-rata perusahaan publik yang melakukan manajemen laba akrual dalam perusahaan sampel adalah 8,50\% terhadap total aset tahun lalu.

Deis dan Giroux (Deis, Jr., and Giroux 1992) belum menjelaskan bahwa probabilitas untuk menemukan pelanggaran tergantung pada kemampuan 
teknis auditor dan probabilitas melaporkan pelanggaran yang tergantung pada kompetensi kemampuan auditor. Rendahnya kualitas auditor pada PTKIN disebabkan karena kompetensi latar belakang pendidikan yang bukan berasal dari akuntan sehingga penguatan berupa capacity building menjadi tidak memiliki pengaruh yang signifikan terhadap Intellectual Capital organisasi. Intellectual Capital pada tatanan organisasi hanya mengkonversi secara personal dari adanya capacity building. Tetapi secara komprehensif ketika Capasity Building dimediasi kualitas audit tidak menunjukkan hasil yang baik.

Teoh dan Wong (Teoh and Wong 1993) juga memberikan bukti bahwa ERC (Earnings Response Coefficient) perusahaan yang menjadi klien pada kantor audit besar, secara statistik signifikan lebih besar dibandingkan perusahaan yang menjadi klien pada kantor audit kecil. Kantor auditor yang besar menunjukkan kredibilitas auditor yang semakin baik, yang berarti kualitas audit yang dilakukan semakin baik pula (Hogan 1997); (Teoh and Wong 1993). Sutton, S.G. (Sutton 1993) telah melakukan penelitian mengenai pengukuran kualitas audit pada tahap proses. Penelitian yang dilakukan oleh Mock dan Samet (Mock and Samet 1982) mengembangkan daftar faktorfaktor kualitas audit potensial dari literatur yakni screening yang digunakan oleh auditor dan survey auditor untuk mengevaluasi daftar tersebut. Meier dan Fuglister (Fuglister 1992) mengungkapkan bahwa kualitas audit menurut konsep kos kualitas tradisional yang terdiri dari 3 (tiga) kategori aktivitas yang perlu dianalisis. Kategori itu adalah persiapan, penilaian dan aktivitas kegagalan. 
Setyo Budi Hartono

\section{Simpulan}

Dari pengujian sampel yang dilakukan terhadap para auditor PTKIN di Indonesia dengan rata-rata penugasan yang masih di bawah 3 tahun dapat disimpulkan:

1. Capacity Building (CB) berpengaruh positif terhadap Audit Quality (AQ). Capacity Building dapat meningkatkan kemampuan dan kualitas para auditor, indikasi yang sama ditunjukkan pada penelitian Trisdiono melalui diklat Capacity Building audit mutu internal pada level pelaksana, kemampuan teknis terutama Pengendalian Mutu dan Teknis agar menciptakan kemampuan yang merata. Capacity Building dapat meningkatkan kemampuan dalam bidang audit yang akan mempengaruhi kualitas hasil akhir pemeriksaan melalui kualitas Laporan Hasil Pemeriksaan Kinerja.

2. Audit Quality (AQ) berpengaruh negatif terhadap Intellectual Capital (IC). Pengaruh negatif ini disebabkan latar belakang pendidikan auditor yang tidak sesuai. Hal ini sependapat dengan Christiawan Yulius Jogi, yang menganggap bahwa kualitas audit ditentukan oleh kompetensi dan independensi. Perbedaan latar belakang ini menyebabkan auditor tidak bisa menjalankan tugas dengan baik walaupun masa perikatan (audit tenure) panjang karena bidang audit, afiliasi, spesialisasi, pengalaman, keahlian, unit yang diaudit, dan besaran anggaran yang diaudit tidak dilakukan secara menyeluruh.

3. Capacity Building (CB) berpengaruh positif terhadap Intellectual Capital (IC). Dalam penelitian Anzam., diungkapkan bahwa Capacity Building dapat meningkatkan kemampuan auditor baik individu, group, organisasi, komunitas dan masyarakat. Sedangkan Brown dan Duguid berargumen bahwa Intellectual Capital organisasi berasal dari pengetahuan organisasi dari berbagi praktik-praktik sosial anggotanya, konfigurasi human resources yang meningkatkan modal sosial organisasi 
dalam memberikan kontribusi yang signifikan dari daya potensi dengan membangun intensitas kapasitas bagi human resource.

4. Tidak ada pengaruh Capacity Building (CB) terhadap Intellectual Capital (IC) dengan menggunakan Audit Quality (AQ) sebagai variabel intervening dapat diketahui kriteria model fit telah terpenuhi. Audit Quality (AQ) berasal dari latar belakang pendidikan personal yang sesuai dengan bidang akuntan telah memberikan pengaruh terhadap akuisisi bagi afiliasi KAP (Big Four), spesialisasi, tenor masa kerja, client importance, dan kematangan emosional. Walaupun kemampuan personal meningkat melalui Capacity Building, tetapi secara merger maupun akuisisi dalam bidang audit, afiliasi, spesialisasi, pengalaman, keahlian, unit yang diaudit, dan besaran anggaran yang diaudit tidak bisa dilakukan secara menyeluruh.

Penelitian ini dilakukan pada audit internal PTKIN yang masih memiliki jam terbang belum tinggi dan pendidikan bukan dari akuntan. Perlu dilakukan kajian ulang terhadap kualitas auditor dari PTN dan PTS di luar Kementerian Agama untuk menguji apakah latar belakang pendidikan berpengaruh terhadap profesi mereka.

\section{Daftar Pustaka}

A.L. Watkins, W. Hillison and S. E. Morecroft. 2005. “Audit Quality: A Synthesis of Theory and Empirical Evidence." Journal of Accounting Literature, 15393.

Acock, Alan C. 2008. A Gentle Introduction to Stata. 2nd editio. Texas: Stata Press Publication, StataCorp LP.

Balsam, Steven, Jagan Krishnan, and Joon S. Yang. 2003. "Auditor Industry Specialization and Earnings Quality." AUDITING: A Journal of Practice \& Theory 22 (2): 71-97. https://doi.org/10.2308/aud.2003.22.2.71.

Bamber, E. Michael, and Linda Smith Bamber. 2009. "Discussion of Quot; Mandatory Audit Partner Rotation, Audit Quality, and Market Perception: 
Evidence from Taiwan." Contemporary Accounting Research 26 (2). Blackwell Publishing Ltd: 393-402. https://doi.org/10.1506/car.26.2.3.

Barney, Jay. 1991. "Firm Resources and Sustained Competitive Advantage." Journal of Management 17 (1): 99-120. https://doi.org/10.1177/ 014920639101700108.

Beasley, Mark S. 1996. "An Empirical Analysis of the Relation between the Board of Director Composition and Financial Statement Fraud." The Accounting Review 71 (4). American Accounting Association: 443-65. https://doi.org/10.2307/248566.

Becker, Connie L., Mark L. Defond, James Jiambalvo, and K.R. Subramanyam. 1998. "The Effect of Audit Quality on Earnings Management." Contemporary Accounting Research 15 (1). Blackwell Publishing Ltd: 124. https://doi.org/10.1111/j.1911-3846.1998.tb00547.x.

Brown, John Seely, and Paul Duguid. 2001. "Knowledge and Organization: A Social-Practice Perspective." Organization Science 12 (2). INFORMS: 198213. https://doi.org/10.1287/orsc.12.2.198.10116.

Chen, Charles J.P., and Bikki Jaggi. 2000. "Association between Independent Non-Executive Directors, Family Control and Financial Disclosures in Hong Kong." Journal of Accounting and Public Policy 19 (4-5). Elsevier: 285-310. https://doi.org/10.1016/S0278-4254(00)00015-6.

Christiawan, Yulius Jogi. 2002. "Kompetensi dan Independensi Akuntan Publik: Refleksi Hasil Penelitian Empiris Institute of Research and Community Outreach." Jurnal Akuntansi Dan Keuangan Indonesia 4 (2): 79-92. http://jurnalakuntansi.petra.ac.id/index.php/aku/article/view/ 15692.

Coates, Charles J., Robert E. Florence, and Kristi L. Kral. 2002. "Financial Statement Audits, a Game of Chicken?" Journal of Business Ethics 41 (1/2). Kluwer Academic Publishers: 1-11. https://doi.org/10.1023/ A:1021355104022.

Dahlan, Muhammad. 2009. "Analisis Hubungan antara Kualitas Audit dengan Diskresioneri Akrual dan Kebebasan Auditor." Working Paper in Accounting and Finance.

David F Larcker, Scott A Richardson and Al Tuna. 2005. "How Important Is Corporate Governance?" Working Paper. University of Pennsylvania. 
DeAngelo, Linda Elizabeth. 1981. "Auditor Size and Audit Quality." Journal of Accounting and Economics 3 (3). North-Holland: 183-99. https://doi.org/10.1016/0165-4101(81)90002-1.

Deegan, Craig Michael. 2004. Financial Accounting Theory. Sydney: McGrawHill Book Company.

Deis, Donald R., Jr., and Gary A. Giroux. 1992. “Determinants of Audit Quality in the Public Sector." The Accounting Review 67 (2). American Accounting Association: 462-79. https://doi.org/10.2307/247972.

Fairchild, Richard J. 2007. "Does Audit Tenure Lead to More Fraud? A GameTheoretic Approach." SSRN Electronic Journal, June. https://doi.org/ 10.2139/ssrn.993400.

Faisal, Nardiyah dan M. Rizal Yahya. 2012. "Pengaruh Kompetensi, Independensi dan Profesionalisme terhadap Kualitas Audit dengan Kecerdasan Emosional sebagai Variabel Moderasi (Survei pada Kantor Akuntan Publik di Indonesia)." Jurnal Administrasi Akuntansi, no. 1.

Francis, Jere R. 2004. "What Do We Know about Audit Quality?" The British Accounting Review 36 (4). Academic Press: 345-68. https://doi.org/ 10.1016/J.BAR.2004.09.003.

Fuglister, H.H. Meier and J. 1992. "How to Improve Audit Quality: Perceptions of Auditors and Clients." The Ohio CPA. Journal, 21-24.

Geiger, Marshall A., and Dasaratha V. Rama. 2006. "Audit Firm Size and GoingConcern Reporting Accuracy." Accounting Horizons 20 (1): 1-17. https://doi.org/10.2308/acch.2006.20.1.1.

Ghosh, Aloke, and Doocheol Moon. 2005. "Auditor Tenure and Perceptions of Audit Quality." The Accounting Review 80 (2): 585-612. https://doi.org/ 10.2308/accr.2005.80.2.585.

Giri, Efraim Ferdinan. 2010. “Pengaruh Tenur Kantor Akuntan Publik (KAP) dan Reputasi KAP terhadap Kualitas Audit: Kasus Rotasi Wajib Auditor di Indonesia." Simposium Nasional Akuntansi Purwokerto XIII.

Gómez-Aguilar, Emiliano Ruiz-Barbadillo and Nieves. 2008. "Does Auditor Tenure Improve Audit Quality? Mandatory Auditor Rotation versus Long Term Auditing: An Empirical Analysis." Working Paper. University of Cadiz Spain. 
Setyo Budi Hartono

Gray, Rob, Reza Kouhy, and Simon Lavers. 1995. "Corporate Social and Environmental Reporting." Accounting, Auditing \& Accountability Journal 8 (2): 47-77. https://doi.org/10.1108/09513579510146996.

Gul, Ferdinand A., Simon Yu Kit Fung, and Bikki Jaggi. 2009. “Earnings Quality: Some Evidence on the Role of Auditor Tenure and Auditors' Industry Expertise." Journal of Accounting and Economics 47 (3). North-Holland: 265-87. https://doi.org/10.1016/J.JACCEC0.2009.03.001.

Herusetya, Antonius. 2012. "Analisis Audit Quality Metric Score (AQMS) sebagai Pengukur Multidimensi Kualitas Audit terhadap Manajemen Laba dan Kandungan Informasi Laba." Disertasi Program Pascasarjana Ilmu Akuntansi. Fakultas Ekonomi, Universitas Indonesia.

Hiroyuki Itami Roehl and Thomas W. 1991. Mobilizing Invisible Assets. Cambridge: Harvard University Press.

Hogan, Chris E. 1997. "Costs and Benefits of Audit Quality in the IPO Market: A Self-Selection Analysis." The Accounting Review 72 (1). American Accounting Association: 67-86. https://doi.org/10.2307/248223.

Holbert, Bob. 2014. "Review of BPK's Performance Audit Methodology."

Ikujiro Nonaka Takeuchi and Hirotaka. 1995. The Knowledge-Creating Company: How Japanese Companies Create the Dynamics of Innovation. New York: Oxford University Press.

Jay B. Barney Arikan and Asli M. 2001. "The Resource-Based View: Origins and Implication." In The Blackwell Handbook of Strategic Management, edited by R. Edward Freeman and Jeefrey S. Harrison Michael A. Hitt, 124-88. Oxford: Black Publishing.

Kock, Ned. 2010. "Using WarpPLS in E-Collaboration Studies." International Journal of E-Collaboration 6 (4): 1-11. https://doi.org/10.4018/ jec.2010100101.

Latan, Imam Ghozali dan Hengky. 2014. Partial Least Square Konsep Metode Dan Aplikasi Penggunaan WarpPLS 4.0. Semarang: Badan Penerbit UNDIP.

Levitt, Arthur. 2000. "Renewing the Covenant with Investors. Speech before the , May 10."

Mahfud Sholihin dan Dwi Ratmono. 2014.Analisis SEM-PLS dengan WARPPLS 3.0. Yogyakarta: Andi Offset. 
Martin L.W. Hall. 1998. "The Confusion of the Capitals: Surveying the Cluttered Landscape of Intellectual 'Capitals' and Terminology." In Profiting from Intellectual Capital, edited by Sullivan Patrick H., 76-83. New York: John Wileys \& Sons Inc.

Mentz, J.C.N. 1997. "Personal and Institutional Factors in Capacity Building and Institutional Development.” Working Paper No. 14. Maastrict.

Mgbame, Chijoke Oscar, Chijoke Oscar Mgbame, Emmanuel Eragbhe, and Nosakhare Peter Osazuwa. 2009. "European Journal of Business and Management EJBM." European Journal of Business and Management 4 (7). International Institute for Science, Technology and Education (IISTE): 154-62. http://iiste.org/Journals/index.php/EJBM/article/view/1823.

Mock, Theodore J., and Michael G. Samet. 1982. "A Multi-Attribute Model for Audit Evaluation." Journal of Accounting Research, 99-112.

Permana, Klaudia Xary. 2012. "Pengaruh Masa Perikatan Audit dan Ukuran KAP terhadap Kualitas Audit." Skripsi. Universitas Diponegoro Semarang.

Pulic, Ante, and Marko Kolakovic. 2003. "Value Creation Efficiency in the New Economy." Global Business and Economics Review 5 (1): 111. https://doi.org/10.1504/GBER.2003.006201.

Reynolds, J.Kenneth, and Jere R Francis. 2000. "Does Size Matter? The Influence of Large Clients on Office-Level Auditor Reporting Decisions." Journal of Accounting and Economics 30 (3). North-Holland: 375-400. https://doi.org/10.1016/S0165-4101(01)00010-6.

Sekaran, Uma. 2003. Research Methods For Business: A Skill Building Aproach. New York-USA: John Wiley and Sons, Inc.

Shadreck, Mandina and Chiheve Hebert. 2013. "Quality And Accountability In Education: What Say The School Heads?" Educational Research International 2 (2): 165-73. http://erint.savap.org.pk/vol2n2.html.

Siregar, Sylvia Veronica, Fitriany Fitriany, Arie Wibowo, and Viska Anggraita. 2011. "Rotasi dan Kualitas Audit: Evaluasi atas Kebijakan Menteri Keuangan KMK No. 423/KMK.6/2002 tentang Jasa Akuntan Publik." Jurnal Akuntansi Dan Keuangan Indonesia 8 (1): 1-20. https://doi.org/ 10.21002/jaki.2011.01.

Sutton, Steve G. 1993. "Toward an Understanding of the Factors Affecting the Quality of the Audit Process." Decision Sciences 24 (1). Blackwell 
Setyo Budi Hartono

Publishing Ltd: 88-105. https://doi.org/10.1111/j.1540-5915.1993. tb00464.x.

Teoh, Siew Hong, and T. J. Wong. 1993. "Perceived Auditor Quality and the Earnings Response Coefficient." The Accounting Review 68 (2). American Accounting Association: 346-66. https://doi.org/10.2307/248405.

Watts, Ross L., and Jerold L. Zimmerman. 1990. "Positive Accounting Theory: A Ten Year Perspective." The Accounting Review 65 (1). American Accounting Association: 131-56. https://doi.org/10.2307/247880.

Yeremias, T Keban. 2004. Enam Dimensi Strategis Admistrasi Publik, Konep, Teori, Dan Isu. Yogyakarta: Gava Media.

Youndt, Mark A., Mohan Subramaniam, and Scott A. Snell. 2004. "Intellectual Capital Profiles: An Examination of Investments and Returns*." Journal of Management Studies 41 (2). Blackwell Publishing Ltd.: 335-61. https://doi.org/10.1111/j.1467-6486.2004.00435.x. 